E3S Web of Conferences 1, 02004 (2013)

DOI: $10.1051 / \mathrm{e} 3$ sconf/20130102004

C) Owned by the authors, published by EDP Sciences, 2013

\title{
Mercury emissions from flooded soils and sediments in Germany are an underestimated problem: challenges for reliable risk assessments and management strategies
}

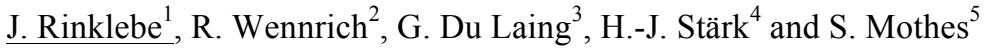 \\ ${ }^{1}$ University of Wuppertal, Soil- \& Groundwater-Management, Pauluskirchstr. 7, 42285 Wuppertal, GERMANY, \\ rinklebe@uni-wuppertal.de \\ ${ }^{2}$ UFZ-Helmholtz Centre for Environmental Research, Department of Analytical Chemistry, Permoserstr. 15, 04318 \\ Leipzig, GERMANY, rainer.wennrich@ufz.de \\ ${ }^{3}$ Faculty of Bioscience Engineering, Ghent University, Coupure Links 653, 9000 Gent, BELGIUM, \\ Gijs.DuLaing@UGent.be \\ ${ }^{4}$ UFZ-Helmholtz Centre for Environmental Research, Department of Analytical Chemistry, Permoserstr. 15, 04318 \\ Leipzig, GERMANY, ha-jo.staerk@ufz.de \\ ${ }^{5}$ UFZ-Helmholtz Centre for Environmental Research, Department of Analytical Chemistry, Permoserstr. 15, 04318 \\ Leipzig, GERMANY, sibylle.mothes@ufz.de
}

\begin{abstract}
Environmental pollution by mercury is a world-wide problem. Particularly floodplain ecosystems are frequently affected. One example is the Elbe River in Germany and its catchment areas; large amounts of $\mathrm{Hg}$ from a range of anthropogenic and geogenic sources have been accumulated in the soils of these floodplains. They serve as sink for $\mathrm{Hg}$ originating from the surface water of adjacent river. Today, the vastly elevated $\mathrm{Hg}$ contents of the floodplain soils at the Elbe River often exceed even the action values of the German Soil Conservation Law. This is especially important as Hg polluted areas at the Elbe River achieve several hundred square kilometres. Thus, authorities are coerced by law to conduct an appropriate risk assessment and to implement practical actions to eliminate or reduce environmental problems. A reliable risk assessment particularly with view to organisms (vegetation as green fodder and hay production, grazing and wild animals) to avoid the transfer of $\mathrm{Hg}$ into the human food chain, requires an authentic determination of $\mathrm{Hg}$ fluxes and their dynamics since gaseous emissions from soil to atmosphere are an important pathway of $\mathrm{Hg}$. However, reliable estimates of $\mathrm{Hg}$ fluxes from the highly polluted floodplain soils at the Elbe River and its tributaries, and its influencing factors are scarce. For this purpose, we have developed a new method to determine mercury emissions from soils at various sites. Our objectives were i) to quantify seasonal variations of total gaseous mercury (TGM) fluxes for floodplain soils at the Elbe River, ii) to provide insights into physico-chemical processes regulating these TGM fluxes, and iii) to quantify the impacts of the controlling factors soil temperature and soil water content on $\mathrm{Hg}$ volatilization from a typical contaminated floodplain soil within soil microcosm experiments under various controlled temperature and moisture conditions. Our study provides insight into TGM emissions from highly Hg-polluted floodplain soils in Germany and that those emissions are an underestimated problem. Current needs for reliable risk assessments, the induced implications for authorities, and future challenges will be discussed. The presented data will contribute to a better understanding of seasonal dynamics of $\mathrm{Hg}$ fluxes and its controlling factors. This presentation should be of large interest for a wide international audience, such as environmental scientists and managers, applied ecologists, and authorities.
\end{abstract}

Key words: Mercury volatilization, Hg soil-air exchange, total gaseous mercury (TGM) seasonality, wetland soils, Elbe River

\section{Introduction}

Mercury $(\mathrm{Hg})$ is one of the most hazardous heavy metals, posing a risk to humans and environment (e.g., Wolfe et al., 1998). It is distributed widespread all over the world and can be found in various environmental compartments 
such as floodplains (e.g., Devai et al., 2005; Overesch et al., 2007; Rinklebe et al., 2009). Many floodplain soils have accumulated large amounts of $\mathrm{Hg}$ as a result of atmospheric deposition or through transport from the watershed (e.g., Boening, 2000; During et al., 2009; Rinklebe et al., 2010).

One example is the Elbe River in Germany and its catchment areas; large amounts of heavy metals including $\mathrm{Hg}$ from a range of anthropogenic and geogenic sources have been accumulated in the soils of these floodplains (Rinklebe et al., 2009, 2010).

However, reliable estimates of $\mathrm{Hg}$ fluxes from the highly polluted floodplain soils at the Elbe River and its tributaries, and its influencing factors are scarce. Therefore the objectives of our study were i) to quantify seasonal variations of TGM fluxes for floodplain soils of the Elbe River and its tributary Saale in Germany, ii) to provide insights into physico-chemical processes regulating these TGM fluxes, and iii) to quantify the impacts of the controlling factors soil temperature and soil water content on $\mathrm{Hg}$ volatilization from a typical contaminated floodplain soil within soil microcosm experiments under various controlled temperature and moisture conditions.

\section{Materials and Methods}

The study sites are situated in floodplains at the Central Elbe River in Germany. The sites have been selected after large-scale conventional soil mapping and many years of comprehensive field pedological research in the floodplains of the Elbe River (e.g. Rinklebe et al., 2007).

Mercury emissions were measured between November 2005 and November 2006. The dataset was collected during seven sampling campaigns, which contained all seasons. Soil microcosm experiments under definite temperature and soil water conditions were carried out to study the impact of the main controlling factors on $\mathrm{Hg}$ emission from the soils (Rinklebe et al., 2009; 2010). To measure TGM emissions, the system described by Rinklebe et al. (2009), modified from Böhme et al. (2005), was used. Advantages of this system were described by During et al. (2009) and Rinklebe et al. (2009).

\section{Results and Discussion}

Mercury emission rates, mean soil temperatures and soil water contents are plotted as a function of sampling time in Fig. 1. Please note, field measurements could not be carried out when the study sites were flooded (e.g. particularly site 6 , Fig. 4/ F). Standard deviations of the three or four replicates (per measurement) range between 110 and $276 \mathrm{ng} \mathrm{m}^{-2} \mathrm{~h}^{-1}$ (with a pumped volume of $60 \mathrm{~L}$ ) and 63 to $162 \mathrm{ng} \mathrm{m}^{-2} \mathrm{~h}^{-1}$ (with a pumped volume of 120
L).

All study sites (except site 6, Fig. 1/ F) reveal seasonal variations of measured $\mathrm{Hg}$ emission rates, soil temperature, and soil water content. Emissions of TGM at each study site tend to be higher during summer (Fig. 1/ A- E), although fairly high $\mathrm{Hg}$ fluxes were observed at study area 'Sandau' in November 2006 (Fig. 1/ D and E). A peak of TGM emission occurred at study site 1 in August 2006. At the same time, the maximum mean TGM emission rate of the replicates was quantified at this site as $849 \mathrm{ng} \mathrm{m}^{-2} \mathrm{~h}^{-1}$ at a flow rate of $60 \mathrm{~L}$ (Fig. 1/ A). The lowest mean TGM emission of $9.7 \mathrm{ng} \mathrm{m}^{-2} \mathrm{~h}^{-1}$ was found in February 2006 at site 2 (Fig. 1/ B). Mercury emission rates measured when using a pumped volume of $60 \mathrm{~L}$ reveal the same seasonal dynamics as those measured when using a pumped volume of $120 \mathrm{~L}$, although differences can be occasionally observed.

In the summer months soil water content decreased while soil temperature and consequently the $\mathrm{Hg}$ volatilization increased. Fluctuating water levels of the Elbe River result in periodic flooding, which in turn have a strong impact on the moisture regime of the soils. In August 2006 (e.g. Fig. 1/ A, B, C) and 11-2006 (e.g. D, $\mathrm{F})$, gently increased soil water contents can be related to high TGM emission rates. However, the impact of soil water content on TGM emission seems to be of less importance compared to the role of soil temperature.

TGM fluxes of our study range between 10 and 849 ng m$~^{-2} \mathrm{~h}^{-1}$ or between 24 and $479 \mathrm{ng} \mathrm{m}^{-2} \mathrm{~h}^{-1}$, for 60 and $120 \mathrm{~L}$ pumped gas volume, respectively. These fluxes are located above background fluxes from unpolluted soils, which rarely increase $10 \mathrm{ng} \mathrm{m}^{-2} \mathrm{~h}^{-1}$ (e.g. Carpi and Lindberg, 1998). However, we found slightly higher TGM values than those measured with a dynamic flux chamber at a soil temperature of $20^{\circ} \mathrm{C}\left(42.7 \mathrm{ng} \mathrm{m}^{-2} \mathrm{~h}^{-1}\right.$, Wallschläger et al., 2002), while the studied soils contained nearly the same contamination level.

Mercury emission seems to increase during summer, when soil temperatures are high (Fig. 1/ A-E). A strong relationship can be observed between TGM and soil temperature, which can be considered as the main controlling factor (except site 1, Fig. 1). This relationship originates from the exponential increase of vapor pressure of $\mathrm{Hg}^{0}$ and $\left(\mathrm{CH}_{3}\right)_{2} \mathrm{Hg}$, as well as the decreasing sorption to the solid soil phase with rising temperatures (Schlüter, 2000). An increase in temperature can be induced by solar radiation, whereas temperature effects can result in diurnal and seasonal variations of TGM emission. Stronger solar radiation in the daytime results in higher temperatures, which affect the $\mathrm{Hg}$ release (Frescholtz and Gustin, 2004).

Relations between temperature and TGM emission are mainly exponential, which has been documented for other sampling sites as well (e.g., Carpi and Lindberg, 1998). 

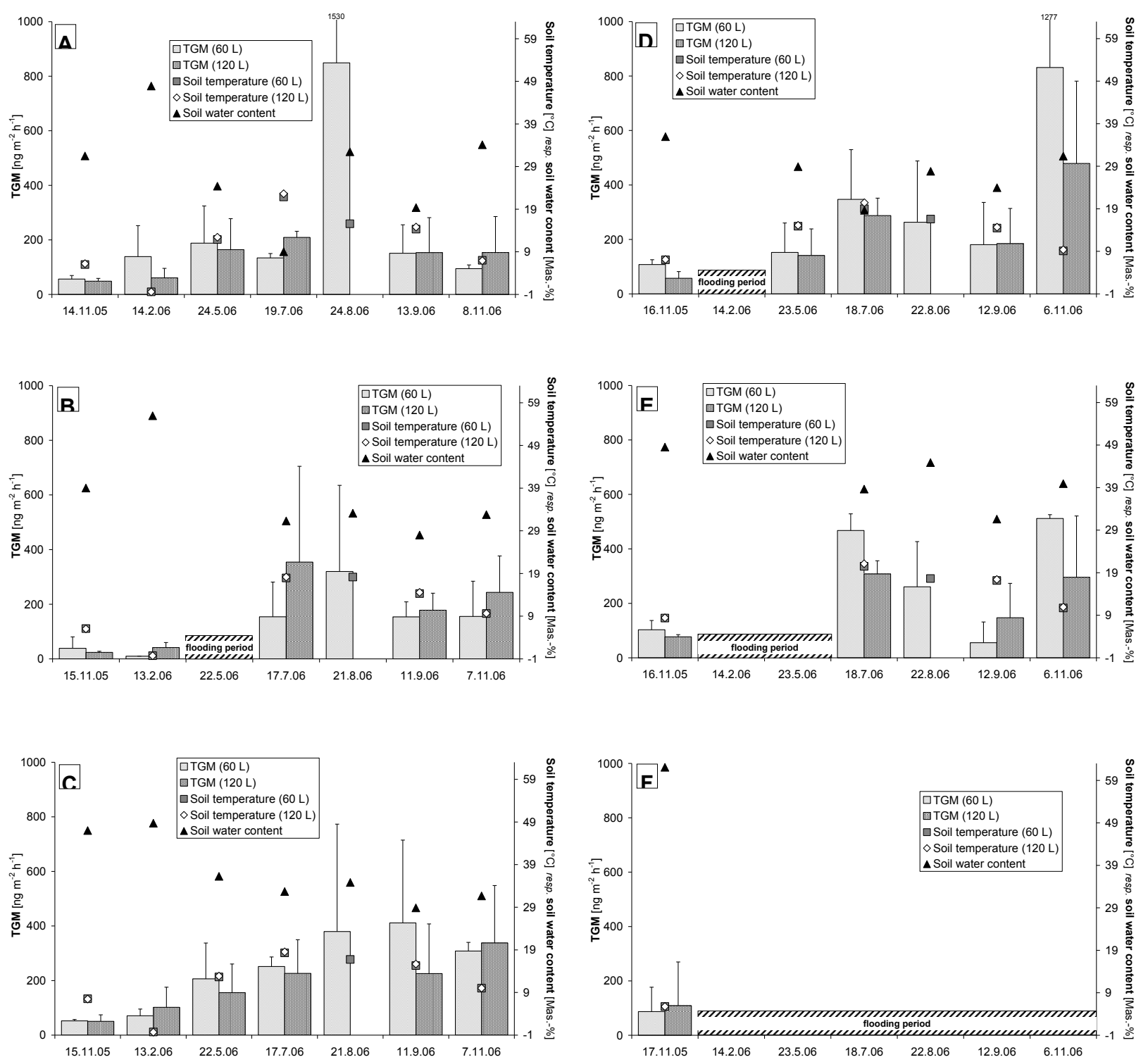

Fig. 1. Dynamics of TGM fluxes (field measurements using a pumped gas volume of 60 resp. $120 \mathrm{~L}$ ), soil temperature and soil water content at $10 \mathrm{~cm}$ depth during sampling appointments at site 1 (A), 2 (B), 3 (C), 4 (D), 5 (E), and site $6(\mathrm{~F})$

The relationship between temperature and TGM emission seems to be site-specific. E.g., a linear instead of exponential correlation between soil temperature and TGM emission rate occurred at site 1, which was also observed by Magarelli and Forstier (2005) in deforested floodplain soils. The fitting of exponential curves to the laboratory data is better, compared to when field data are used. This should be attributed to the fact that other non-controllable factors also affect TGM emission under field conditions, e.g. flooding. The water level of the Elbe River fluctuates extremely, which results in temporarily flooded areas. This in turn influences the water content of the soils, although TGM emissions are not as obviously influenced by this phenomenon as compared to the effect of soil temperature.

Based on the determined mean annual $\mathrm{Hg}$ emission rate of 1.2 to $2.8 \mathrm{mg} \mathrm{m}^{-2} \mathrm{y}^{-1}$, a period between 59 (site 1,
$60 \mathrm{~L}$ ) and 648 years (site 5, $120 \mathrm{~L}$ ) would be needed to bring $\mathrm{Hg}_{\text {tot }}$ in soils lower than the required action value of the German Soil Conservation Law, when taking $\mathrm{Hg}$ output by leaching and $\mathrm{Hg}$ uptake by plants not into account. Nevertheless, an elevated $\mathrm{Hg}$ remobilization potential of those $\mathrm{Hg}$ enriched soils in form of volatile $\mathrm{Hg}$ exists and is affected by soil temperature and water content as well as the interaction of soil characteristic and environmental conditions.

\section{Conclusion}

Soil temperature, soil water content and flood dynamics are considered as important factors of seasonal dynamics of the total gaseous mercury (TGM) fluxes in floodplains. In contrast, mercury concentrations and stocks in top soil, Corg content, $\mathrm{pH}$, and soil texture, however, did not 
show significant correlations with TGM. Rather, we have detected seasonal variations of TGM fluxes due to large fluctuations of soil temperature, soil water content and flood dynamics. $\mathrm{Hg}$ emission rates increased exponentially with raised air and soil temperatures in both field and laboratory experiments. The effect of soil water content was interfered by the effect of soil temperature during field measurements. Wet soil material showed higher TGM fluxes compared to dry soil, whereas the role of soil water content was also affected by sampling time during microcosm experiments. Our study provides insight into TGM emissions from highly $\mathrm{Hg}$-polluted floodplain soils. Moreover, it will contribute to a better understanding of seasonal dynamics of $\mathrm{Hg}$ fluxes and its controlling factors. The presented data should be of large interest for a wide international audience, such as environmental scientists and managers, applied ecologists, environmental and technical engineers, and authorities.

\section{Acknowledgements}

This study was supported by a research grant of the European Fund for Regional Development (EFRE), of the Ministry of Agriculture and Environment, and advised of the Department of Environmental Protection (LAU) of the Federal German state Saxony-Anhalt (FKZ: 76213/01/05). We thank Dr. M. Overesch, Mrs. A. During, Mr. H. Dittrich, and Mr. J. Steffen for technical assistance as well as Analytik Jena AG for supplying the device used to establish the connection of the gold traps with CV-AAS.

\section{References}

Boening DW. Ecological effects, transport, and fate of mercury: a general review. Chemosphere 2000; 40:1335-1351.

Böhme F, Rinklebe J, Stärk HJ, Wennrich R, Mothes S, Neue HU. A simple field method to determine mercury volatilisation from soils. ESPR - Environ Sci \& Poll Res. 2005; 12(3):133-135.

Carpi A, Lindberg SE Application of a TeflonTM dynamic flux chamber for quantifying soil mercury flux: tests and results over background soil. Atmospheric Environ. 1998; 32(5): 873-882.

Devai I, Patrick WH, Neue HU, DeLaune RD,
Kongchum M, Rinklebe J. Methyl Mercury and Heavy Metal Content in Soils of Rivers Saale and Elbe (Germany), Anal. Lett., 2005; 38:1037-1048.

During A, Rinklebe J, Böhme F, Wennrich R, Stärk HJ, Mothes S, Du Laing, G, Schulz E, Neue HU. Mercury Volatilization from Three Floodplain Soils at the Central Elbe River (Germany). Soil Sediment Contam.: Int. J. 2009; 18:429-444.

Frescholtz TF, Gustin MS. Soil and foliar mercury emission as a function of soil concentration. Water, Air, and Soil Poll. 2004; 155:223-237.

Magarelli G., Fostier AH. Influence of deforestation on the mercury air/soil exchange in the Negro River Basin, Amazon. Atmospheric Environ. 2005; 39:7518-7528.

Overesch M, Rinklebe J, Broll G, Neue HU. Metals and arsenic in soils and corresponding vegetation at Central Elbe river floodplains (Germany), Env. Poll., 2007; 145.800-812.

Rinklebe J, Franke C, Neue HU. Aggregation of Floodplain Soils as an Instrument for Predicting Concentrations of Nutrients and Pollutants. Geoderma 2007; 141:210-223.

Rinklebe J, During A, Overesch, M, Wennrich R, Stärk HJ, Mothes S, Neue HU. Optimization of the simple field method to determine mercury volatilization from soils - Examples of 13 sites in floodplain ecosystems at the Elbe River (Germany), Ecol. Eng. 2009; 35:319-328.

Rinklebe J, During A, Overesch M, Du Laing G, Wennrich R, Stärk HJ, Mothes S. Dynamics of mercury fluxes and their controlling factors in large Hg-polluted floodplain areas, Environ. Pollut. 2010; 158: 308-318.

Schlüter K. Review: evaporation of mercury from soils. An intergration and synthesis of current knowledge. Environ Geol. 2000;39:249-271.

Wallschläger D, Kock HH, Schroeder WH, Lindberg SE, Ebinghaus R, Wilken RD. Estimating gaseous mercury from contaminated floodplain soils to the atmosphere with simple field measurement techniques. Water, Air, and Soil Poll. 2002; 135:39-54.

Wolfe MF, Schwarzbach S, Sulaiman RA Effects of mercury on wildlife: A comprehensive review, Environ. Toxicol. Chem. 1998; 17:146-160. 